\title{
Capacity Limitation Control of Multiple Bi-directional DC-DC Converters for Micro Grid Application
}

\author{
S. J. Chiang ${ }^{1}$, Yu-Min Liao ${ }^{2}$, Ke-Chih Liu ${ }^{2}$ \\ ${ }^{1}$ Department of Electrical Engineering, National United University, Taiwan \\ ${ }^{2}$ Chung-Shan Institute of Science and Technology, Taoyuan, Taiwan \\ Correspondence: S. J. Chiang, Department of Electrical Engineering, National United University, Taiwan
}

Received: May 4, 2015 Accepted: June 17, 2015 Online Published: July 2, 2015

doi:10.11114/set.v2i1.926 URL: http://dx.doi.org/10.11114/set.v2i1.926

\begin{abstract}
The micro grid system requires battery for energy storage and power management. In which, the bi-directional DC to DC converter is the key component for maintaining the DC bus voltage and controlling the charge and discharge of the battery with or without grid support. Parallel control of multiple DC to DC converters is a critical technique to enlarge the power capacity. This paper presents two capacity limitation control methods that multiple DC to DC converters can be paralleled with distributed battery banks. The first method is the capacity limitation control with cascaded load current sense needing no control interconnection. The second method is the capacity limitation control with master-slave and cascaded current command limitation. Two methods are presented to solve the limitation of droop control method and active current sharing method respectively, and can be extended without converter number limitation theoretically. Three prototype $240 \mathrm{~W}$ bidirectional half-bridge DC to DC converters are built and paralleled in this paper. The proposed method is confirmed with some measured results.
\end{abstract}

Keywords: capacity limitation, cascaded load current sense, cascaded current command limitation, no control interconnection, master-slave control

\section{Introduction}

Nowadays, due to the flourishing development renewable energy and the demand of saving energy, the micro-grid system (MGS) is more and more attractive (Lasseter, Akhil, Marnay, and Stevens, 2002). Figure 1 shows a typical DC micro-grid system that integrates the PV and wind power converters, DC load, DC and AC load converters, grid inverter and bi-directional DC-DC converter (Beshr, 2013. Xu, He, Qin, and Li, 2012). Due to the power fluctuation feature of the renewable source, the DC MGS usually requires battery to charge or discharge energy for load leveling (Eid, 2013). This power management function is important to support the MGS and help the stability of the public grid. Maintaining the DC bus voltage is the essential thing for instantaneous power balance of the MGS. In which the bi-directional DC to DC converter is the key component for executing the above power balance control (Phattanasak, Kaewmanee, Thounthong, Sethakul, Martin, Pierfederici, and Davat, 2013. Dong, Cvetkovic, Boroyevich, Zhang and Wang, 2013 ).

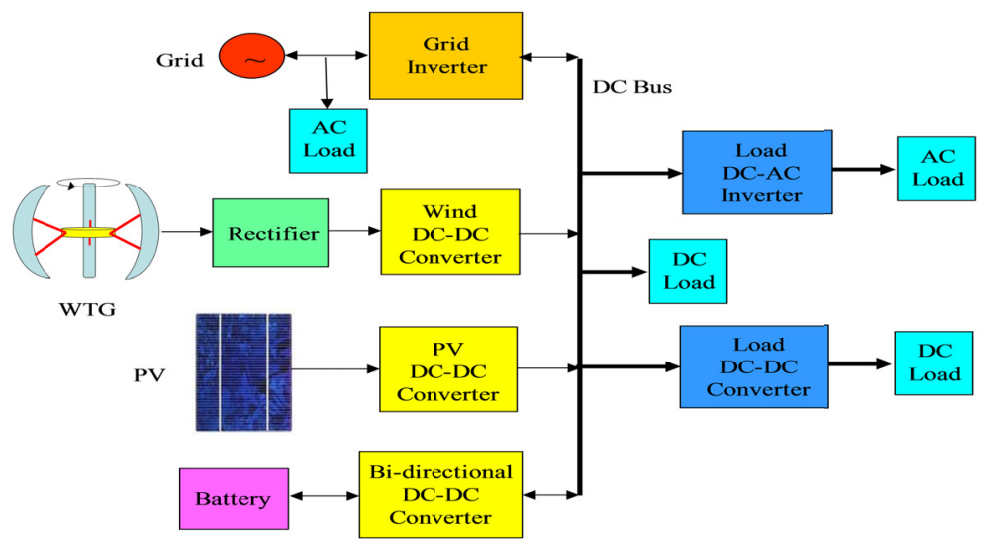

Figure 1. The micro grid system 
Parallel control of multiple DC to DC converters is an important and critical technique for controlling equal current sharing and enlarging the capacity of DC power supply system. There are various control methods for parallel operation of multiple converters as categorized in Figure 2 (Luo, Ye, Lin and Lee. 1999). It is mainly divided into the active current sharing method with control interconnection and the droop method without control interconnection. For the DC micro-grid application the droop method seems to be more suitable than the active current sharing method. It is because: (i) no control interconnection of the droop method makes it easier to achieve the plug and play feature (Nasirian, Davoudi, Lewis, and Guerrero, 2014); (ii) The DC to DC converter in the micro-grid system can be with different capacity, not for equal current sharing. The droop method can provide this kind of power sharing by adjusting the droop impedance (Augustine, Mishra, and Lakshminarasamma, 2015. Lu, Sun, Guerrero, Vasquez, and Huang, 2014. Lu, Sun, Huang, Guerrero, Vasquez, and Xing, 2014); (iii) Some converters may be in charge mode and some converters may be in discharge mode, it is hard to generate the current command of each converter for the active current sharing method. The droop method has the ability to parallel converters with different operation modes (Yu, Huang, Burgos, Li, and Du, 2013). Although the droop method has many advantages over the active current sharing method as stated above, it also has the limitation of poor voltage regulation of the DC bus as compared with the active current sharing method due to the real or virtual impedance in series with the load for adjust the power sharing.

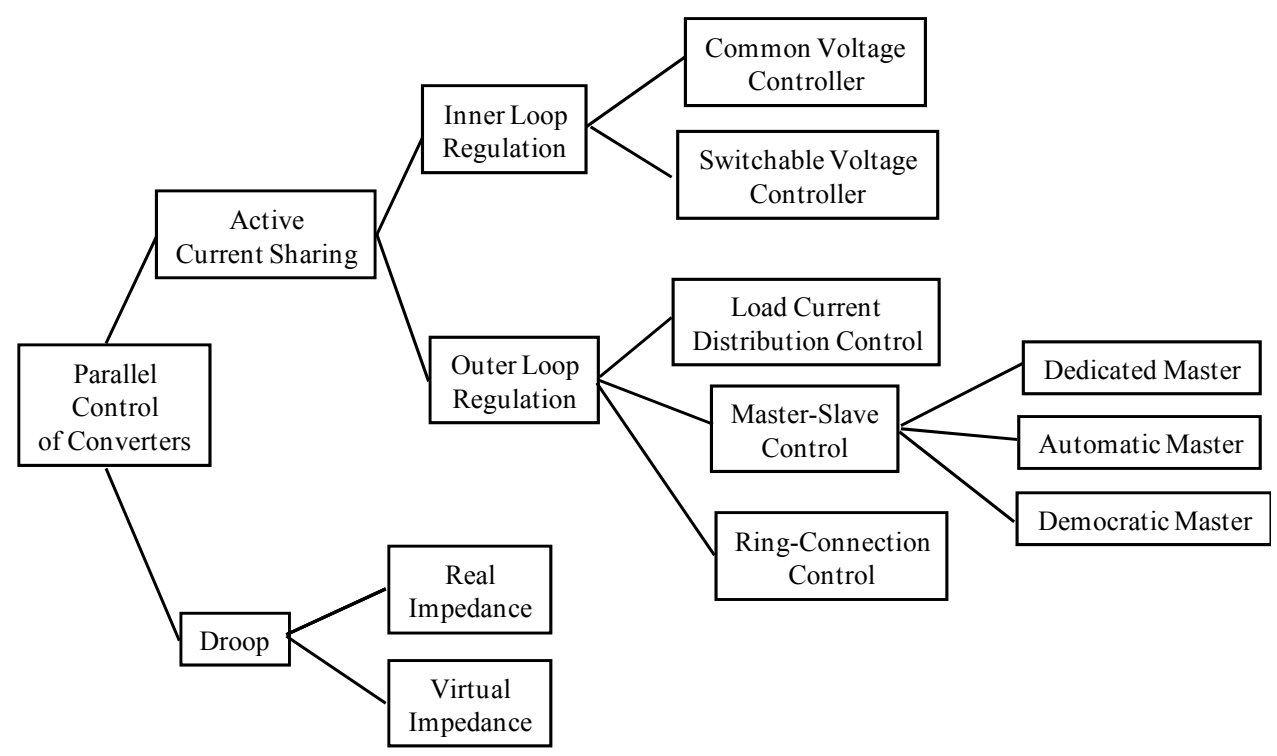

Figure 2. Various control methods for parallel operation of multiple DC-DC converters

This paper presents two capacity limitation control methods for controlling the parallel of converters to solve the limitation of droop method and active current sharing method, respectively. The first method is the capacity limitation control with cascaded load current sense. By using current limitation control of converters near to the load and DC voltage regulation control of the furthest converter, the parallel system can achieve no control interconnection as the droop method and achieve more precise DC bus voltage regulation than the droop method. The second method is the capacity limitation control with master-slave. The master converter is responsible for the voltage regulation of DC bus and generates the total output current command of the converters. By using cascaded current command limitation, it allows the converters be in different operation mode, solving the limitation of the active current sharing method.

To verify the proposed method, three prototype $240 \mathrm{~W}$ bidirectional half-bridge DC to DC converters are built and paralleled. The effectiveness is confirmed with some experimental results.

\section{The proposed Capacity Limitation Control with Series Connection}

The proposed capacity limitation control with cascaded load current sense is shown in Figure 3, in which the load current sensors of the converters are in cascaded connection with the load. Therefore, converter 1 that nearest to the load will detects $I_{L I}=I_{L}$. Converter 2 will detects $I_{L 2}=I_{L 1}-I_{o l}$. The final converter $N$ will detects $I_{L N}=I_{L(N-I)}-I_{o(N-I)}$. The converter employs dual loop control loops with an inner current loop and an outer voltage loop. Only the converter $N$ activates its voltage control loop (in CV control). The other converters only activate the current control loop that the current command is generated from the current limiter (in CC control). The current limiter uses the sensed load current and the operation mode to generate the limited current command. As the sensed load current is larger than the preset limited current level, the converter will export a current equal to the sensed load current. Therefore, the current sharing will be shown as Figure 4. In which four converters are paralleled to maintain the DC bus and the current limited level is set to be $I_{o M}$. The load current is in the range $2 I_{o M}<I_{L}<3 I_{o M}$. So converters 1 and 2 will export current equal to $I_{o M}$, 
the output current of converter 3 will be less than IoM. Ideally, the final converter (converter 4) will export zero load current and therefore have enough capability to regulate the DC bus voltage. To implement the above load current sense and the plug and play feature, a connection box with built-in load current sensors can be set up. The OR-ing diode with bypass switch is required for plug and play in each converter as shown in Figure 3.

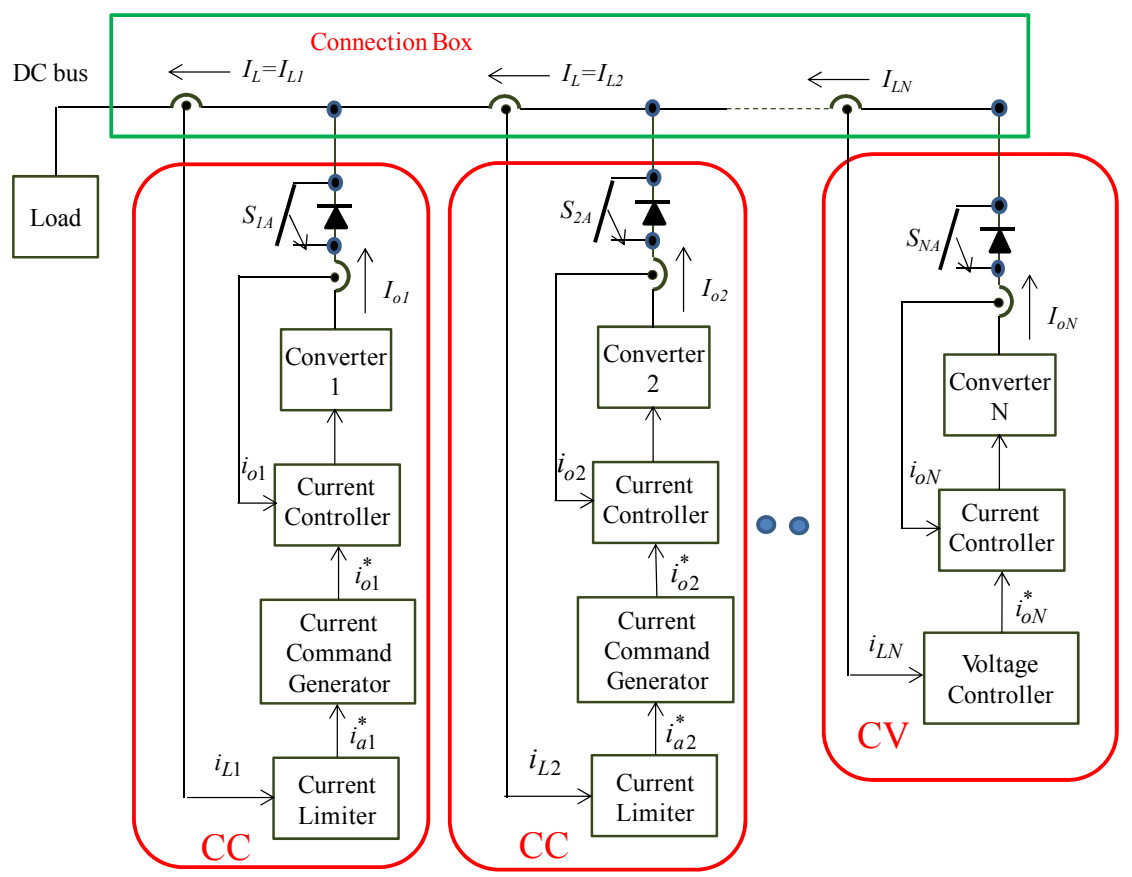

Figure 3. The proposed capacity limitation control with cascaded load current sense

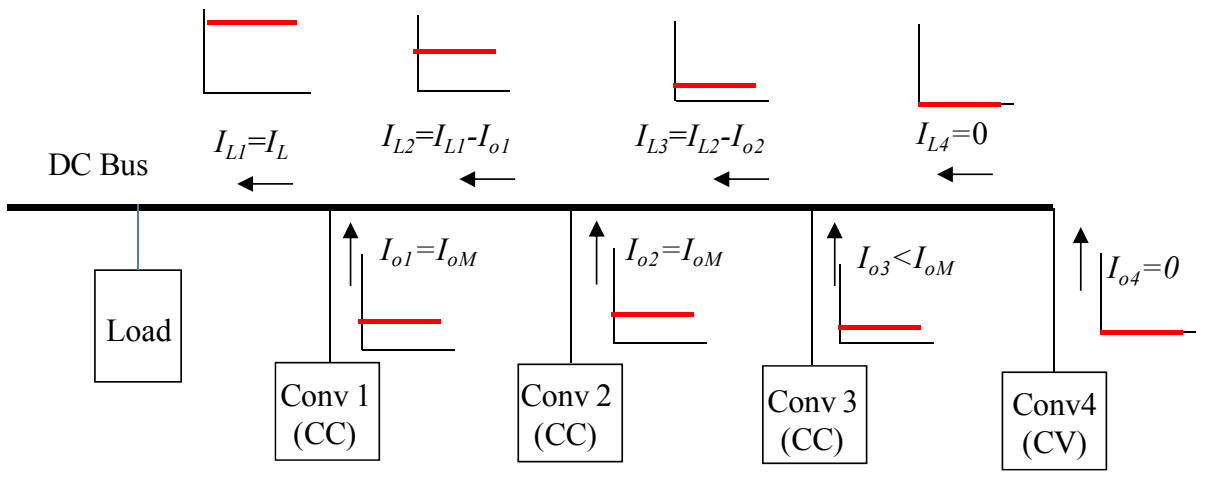

Figure 4. Current sharing of the capacity limitation control with cascaded load current sense

Advantages of the above capacity limitation control with cascaded load current sense include: (i) There is no control interconnection which may introduce control delay or signal noise to cause control system instability; (ii) No control interconnection reduces the setup complexity of the parallel system; (iii) The number of parallel converters is no limit theoretically; (iv) Easy for plug and play design and therefore easy for maintenance. (v) The current limitation level for each converter can be different, converters with different capacity also can be paralleled. The limitation of this control method includes: (i) the converter near the load will sense a lager current, how to do the current sense is an issue; (ii) The connection wire for each converter must be designed to flow the largest load current; (iii) The current sharing is not equal, the converter near to the load will have a shorter life cycle; (iv) It is hard to do the power management of the whole system due to no control interconnection.

\section{The Proposed Capacity Limitation Control with Master-slave And Cascaded Current Command Limitation}

To improve the active current sharing control that converters are hard to be in different operation modes, Figure 5 presents the proposed capacity limitation control with master-slave and cascaded current command limitation. The converter also employs dual control loops with an inner current loop and an outer voltage loop. Only the master converter activates its voltage control loop (in CV control). The other slave converters only activate their current control loop (in CC control). The voltage controller of the master converter (converter 1) generates a current command $i_{o c l}{ }^{*}$ regarding to the total output current command of the parallel system. $i_{o c l}{ }^{*}$ enters a current limiter to produce the current 
command $\left(i_{o l}{ }^{*}\right)$ of the converter 1 . The difference signal $i_{o c 2}{ }^{*}=i_{o c 1}{ }^{*}-i_{o l}{ }^{*}$ are send to the convert 2. $i_{o c 2}{ }^{*}$ then enters the current limiter to generate the current command $i_{o 2}{ }^{*}$ of converter 2 . The difference signal $i_{o c 3}{ }^{*}=i_{o c 2}{ }^{*}-i_{o 2}{ }^{*}$ are sent to the convert 3 . In the same way, the slave converter $(N-1)$ will generate the difference signal $i_{o c N}{ }^{*}$ for the converter $N$. The converter $N$ then uses its current limiter to generate its current command .

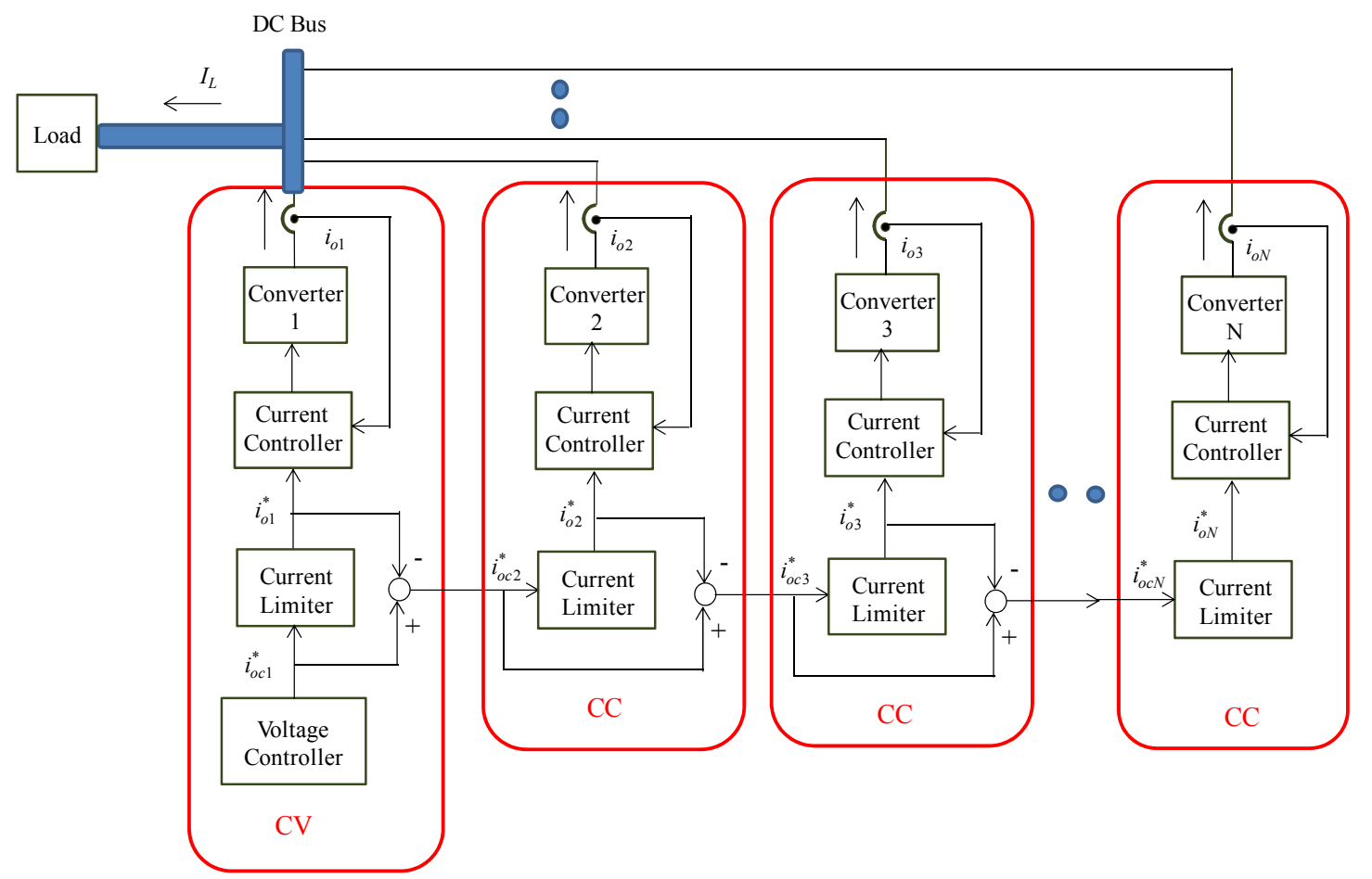

Figure 5. Capacity limitation control with master-slave and cascaded current command limitation

The limit level of the current command limiter can be generated from the battery state of charge (SOC) of the converter or the power management controller of the parallel system. This level can be positive or negative to adopt different operation mode of converters. As this limit level is positive the converter is in discharge mode. On the contrary, if the limit level is negative the converter is in charge mode.

Advantages of the above capacity limitation with master-slave control and cascaded current command limitation include: (i) converters with different operation mode is allowed; (ii) Instead of power wire cascaded connection as Figure 3, Figure 5 employs the signal cascaded connection. The power wire for each converter can be selected not with the total load current but with its own capacity; (iii) There is no need to sense the load current in each converter, simplifying the sensed circuit; (iv) The number of parallel converters is also no limit theoretically; (v) Different capacity converters also can be paralleled. (iv) The power management of the whole system can be performed due to control interconnection. The converter with zero $i_{o c}{ }^{*}$ can be stop to reduce the standby loss to save the battery consumption. However, due to the control interconnection, it still possesses the following disadvantages that are inherent for the active current sharing control: (i) It may introduce control delay or signal noise to cause control system instability; (ii) The control interconnection increases the setup complexity of the parallel system.

\section{Implementation and Verification of The Proposed Control Method}

To verify the above two control methods, in this section three prototype $240 \mathrm{~W}$ bi-directional DC-DC converters with half-bridge topology are implemented. The parameters of the converters are as follow:

$$
\begin{aligned}
V_{b u s}=48 \mathrm{~V}, V_{b a t} & =24 \mathrm{~V}, I_{o, \max }=10 \mathrm{~A} \text { for dicharge mode and }-5 \mathrm{~A} \text { for charge mode, } \\
f_{s} & =50 \mathrm{kHz}, L=100 \mu \mathrm{H}, \mathrm{C}=220 \mu \mathrm{F}
\end{aligned}
$$

Figure 6 shows the designed parallel system configuration using the capacity limitation control with cascaded load current sense based on Figure 3. The other part of the micro-grid system on the DC bus is seen as the load and modeled as a current source $I_{L} . K_{s}(=0.1)$ and $K_{v}(=0.05)$ are the sensing factor of the voltage and current, respectively. Average current mode control is adopted for controlling the inductor current. $G_{C A}$ is the current mode controller. The control voltage $\left(V_{\text {coni }}, i=1,2,3\right)$ generated from the $G_{C A}$ is then compared with the PWM ramp signal $V_{t}$ to generate the gating signal of the switches. 


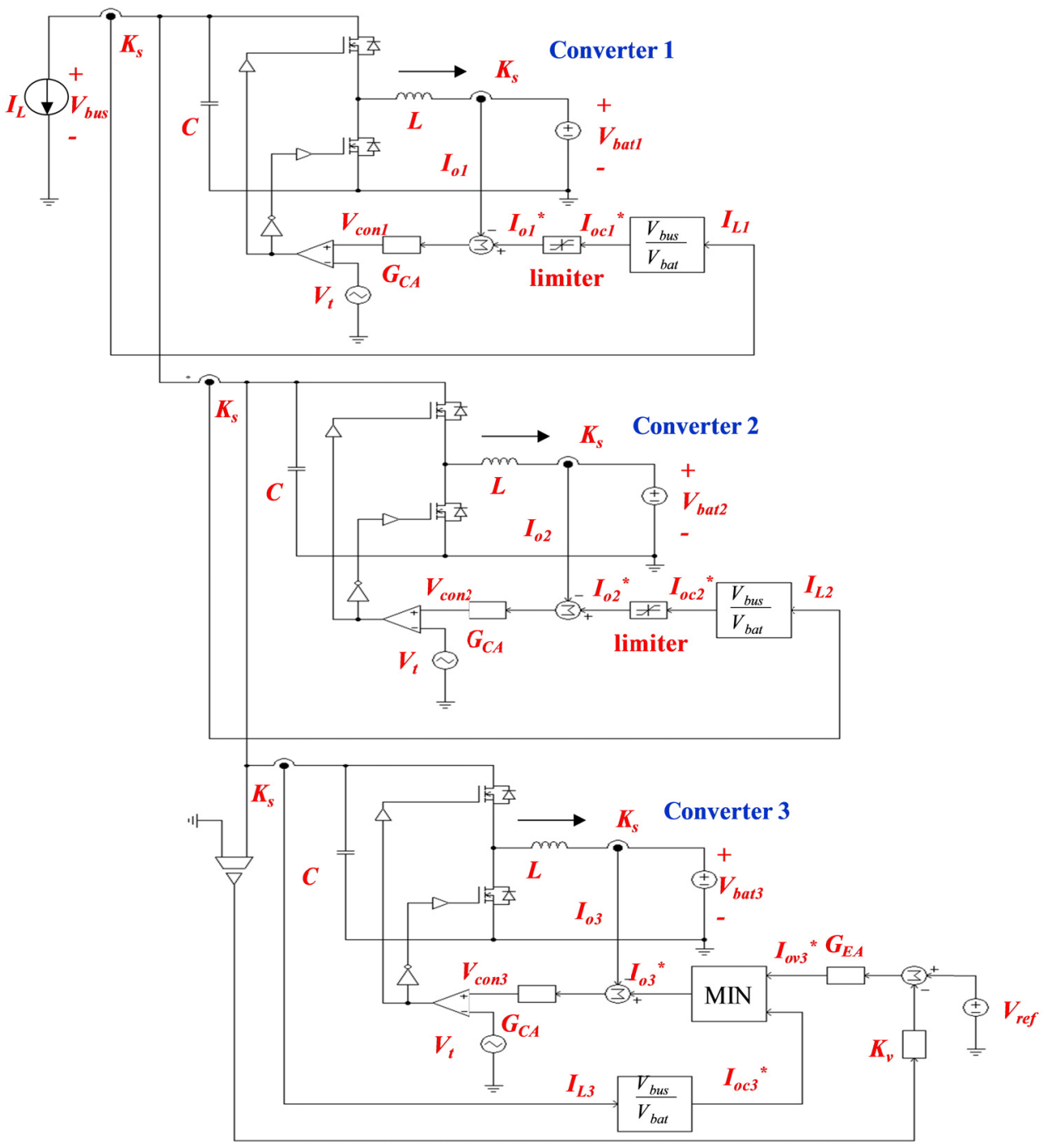

Figure 6. Parallel of 3 half-bridge converters using the capacity limitation control

with cascaded load current sense

Due to be in boost mode that power is transferred from battery to DC bus, the load current $\left(I_{L i}, i=1,2,3\right)$ sensed on the DC bus must be transferred to be the estimated inductor current command $\left(I_{o c i}{ }^{*}, i=1,2,3\right)$ through a gain factor of $V_{\text {bus }} / V_{\text {bat }}$. The estimated inductor current command is limited by a limiter to generate the final inductor current command $\left(I_{o i}{ }^{*}, i=1,2\right)$ of the converters 1 and 2 that in the CC mode. The limited level is set based on the battery SOC (state of charge) and allowable capacity of the converter. As for the converter 3 that operates in the CV mode, the current command $I_{o 3}{ }^{*}$ is generated from the minimum value of the inductor current command $I_{o c 3}{ }^{*}$ and the regulated signal $I_{o v 3}{ }^{*}$ from the voltage controller $\left(G_{E A}\right)$.

The real converter module is shown in Figure 7. Three modules are paralleled in this paper. The controller is implemented with the TI DSP F28335. The control program for each module is designed based on Figure 6 using the PSIM SimCoder toolbox. The limited current level is limited to be $10 \mathrm{~A}$. The electronics load is used to generate $I_{L}$ in the discharging mode. 


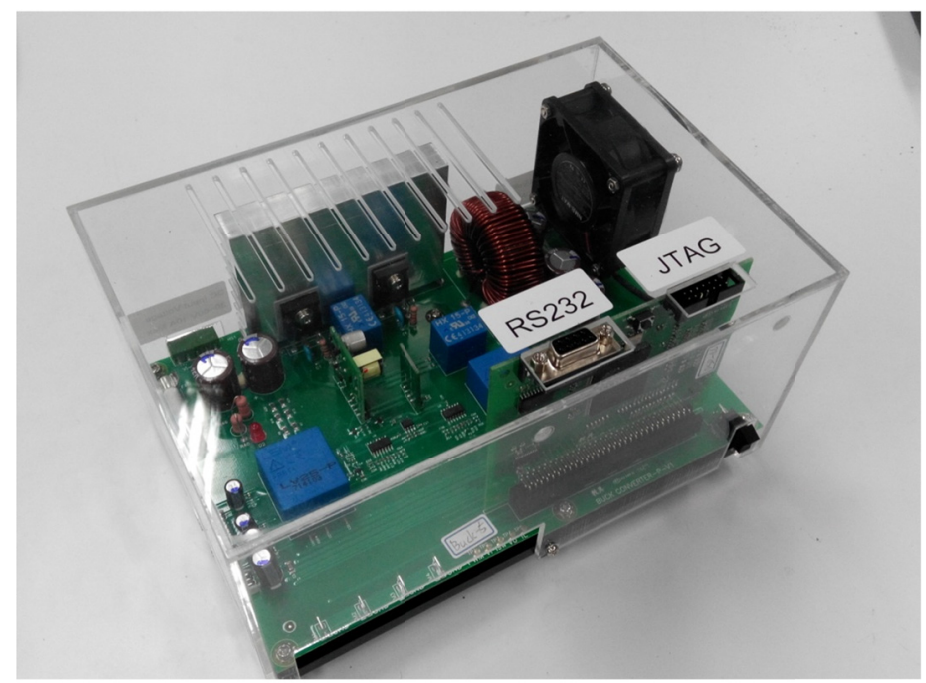

Figure 7. The bi-directional half-bridge DC-DC converter module controlled with DSP control circuit

Figure 8 shows the experimental result that the DC bus current $\left(I_{L}\right)$ is changed from $6 \mathrm{~A}$ to $13 \mathrm{~A}$ (about $288 \mathrm{~W}$ to $625 \mathrm{~W}$ ). The measured results show that initially $\left(I_{L}=6 \mathrm{~A}\right)$ only converter 1 and converter 2 export current. Inductor current of the Converter 1 is limited by the limited level $(10 \mathrm{~A})$. Inductor current of the Converter 2 is $2 \mathrm{~A}$. Inductor current of the Converter 3 is near zero to only supply its own loss. As the DC bus current is changed to be $I_{L}=13 \mathrm{~A}$, inductor currents of the Converter 1 and Converter 2 are limited to $10 \mathrm{~A}$. The rest current is supplied by the Converter 3 . The DC bus voltage is regulated well by the voltage controller of Converter 3 . Theses all confirms the effectiveness of the proposed capacity limitation control with cascaded load current sense.

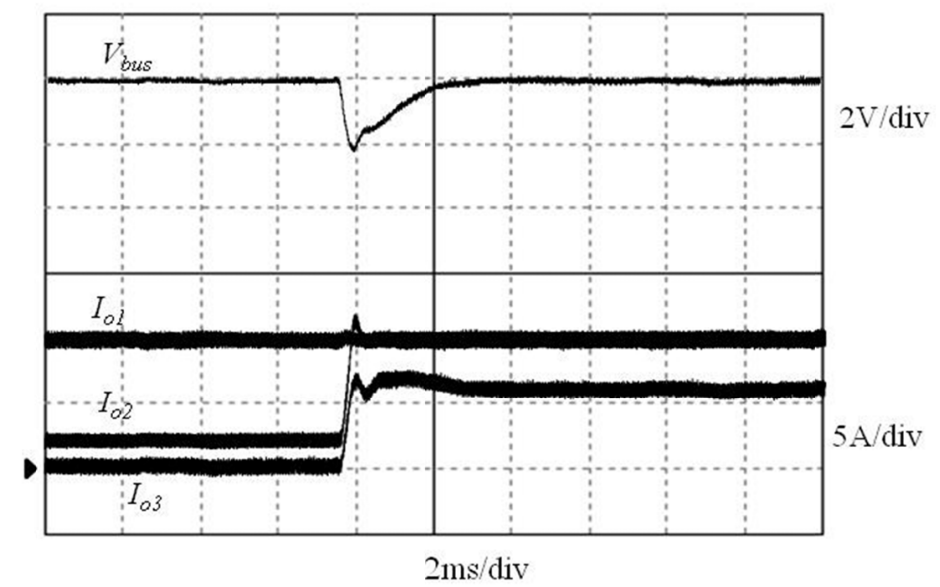

Figure 8. Experimental result of the capacity limitation control with the capacity limitation control with cascaded load current sense ( $I_{L}$ is changed from $6 \mathrm{~A}$ to $\left.13 \mathrm{~A}\right)$

Figure 9 shows the designed parallel configuration using the capacity limitation control with master-slave and cascaded current command limitation based on Figure 5. The same as Figure 6, average current mode control is adopted for controlling the inductor current. $G_{C A}$ is the current mode controller. $G_{E A}$ is the voltage controller of the master converter (converter 1). It regulates the DC bus voltage to generate $I_{o c l}{ }^{*}$ regarding to the total inductor current requirement. $I_{o c l}{ }^{*}$ enters a current limiter to produce the current command $\left(I_{o l}{ }^{*}\right)$ of the converter 1 . The difference signal $I_{o c 2}{ }^{*}=I_{o c 1}{ }^{*}{ }^{*} I_{o I}{ }^{*}$ are send to the convert 2. $I_{o c 2}{ }^{*}$ then enters the current limiter to generate the current command $I_{o 2}{ }^{*}$ of converter 2 . The difference signal $I_{o c 3}{ }^{*}=I_{o c 2}{ }^{*}-I_{o 2}{ }^{*}$ are send to the convert 3 . The converter 3 then uses its current limiter and $I_{o c 3}{ }^{*}$ to generate its current command $I_{o 3}{ }^{*}$. 


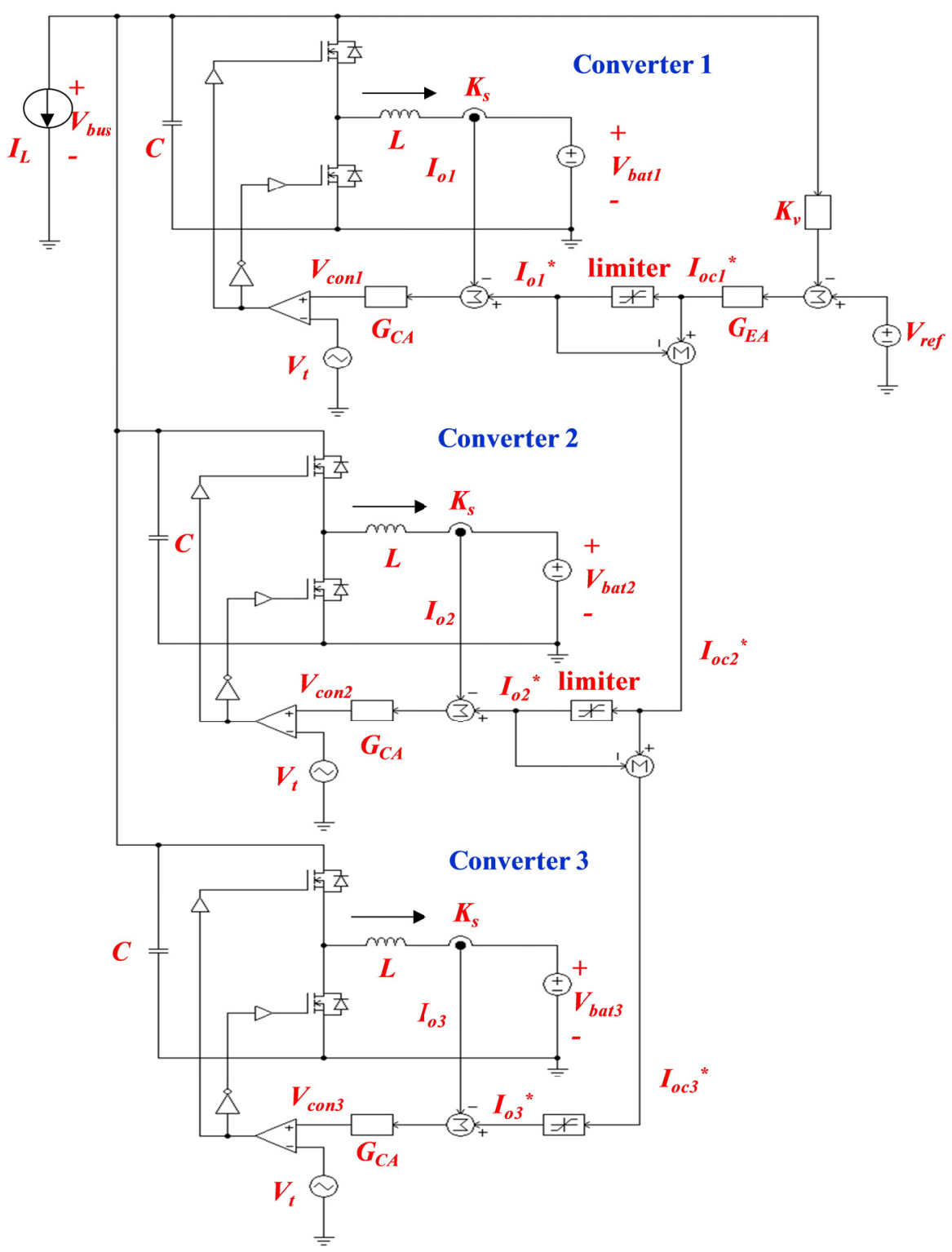

Figure 9. Parallel of 3 half-bridge converters using the capacity limitation control with master-slave and cascaded current command limitation

Figure 10 shows the experimental result that the DC bus load current $\left(I_{L}\right)$ is changed from $6 \mathrm{~A}$ to $13 \mathrm{~A}$. The measured results show that initially $\left(I_{L}=6 \mathrm{~A}\right)$ only converter 1 and converter 2 export current. Inductor current of the Converter 1 is limited by the limited level (10A). Inductor current of the Converter 2 is $2 \mathrm{~A}$. Inductor current of the Converter 3 is near zero to only supply its own loss. As the DC bus current is changed to $I_{L}=13 \mathrm{~A}$, inductor currents of the Converter 1 and Converter 2 are limited to 10A. The rest current is supplied by the Converter 3. The DC bus voltage is regulated well by the voltage controller of Converter 1 . Theses all confirms the power sharing effectiveness of the proposed capacity limitation control with master-slave and cascaded current command limitation. 


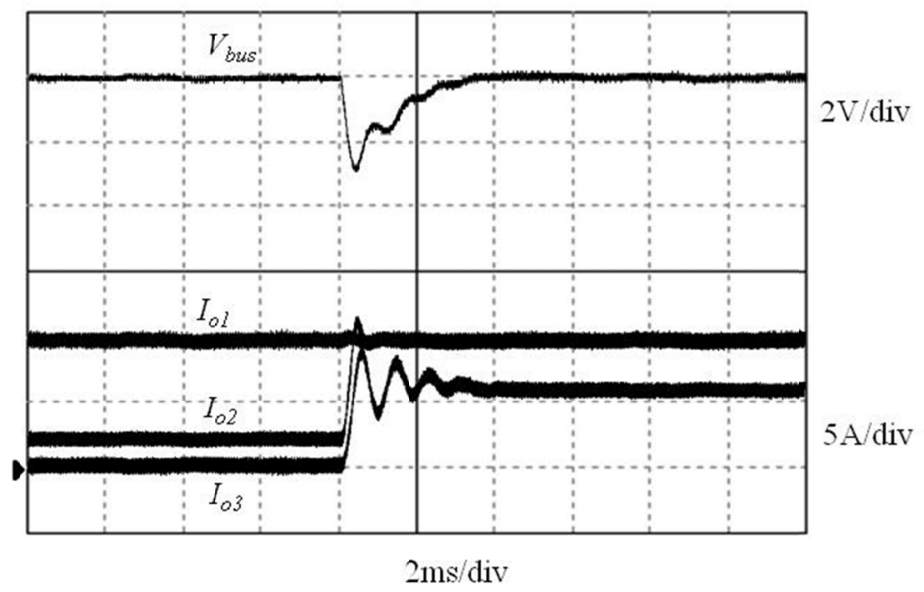

Figure 10. Experimental result of the capacity limitation control with master-slave and cascaded current command limitation (All converters are in discharge mode and $I_{L}$ is changed from 6A to $13 \mathrm{~A}$ )

Figure 11 shows the experimental result that all converters are not in the same operation mode. Converters 1 and 3 are in discharge mode and Converter 2 is in charge mode (the charging current is $I_{o}=-5 \mathrm{~A}, 120 \mathrm{~W}$ ). The DC bus load current $\left(I_{L}\right)$ is changed from $2 \mathrm{~A}(96 \mathrm{~W})$ to $6 \mathrm{~A}(288 \mathrm{~W})$. Seeing Converter 2 in charge mode as a load for Converter 1 and 3 , the total current that Converters 1 and 3 have to export is changed from $4.5 \mathrm{~A}(216 \mathrm{~W})$ to $8.5 \mathrm{~A}(408 \mathrm{~W})$. The measured results show that initially inductor current of the Converter 1 is $I_{o l}=9 \mathrm{~A}(216 \mathrm{~W})$. Inductor current of the Converter 2 is $I_{o 2}=-5 \mathrm{~A}$. Inductor current of the Converter 3 is near zero to only supply its own loss. As the DC bus current is changed to $I_{L}=6 \mathrm{~A}$, inductor currents of the Converter 1 is limited to $I_{o l}=10 \mathrm{~A}$. Inductor current of the Converter 2 is still $I_{o 2}=-5 \mathrm{~A}$. The rest of the load current is supplied by the Converter 3 such that $I_{o 3}=7 \mathrm{~A}$. The DC bus voltage is regulated well by the voltage controller of Converter 1. Theses all confirms the power sharing effectiveness of the proposed capacity limitation control with master-slave and cascaded current command limitation operated in different operation modes.

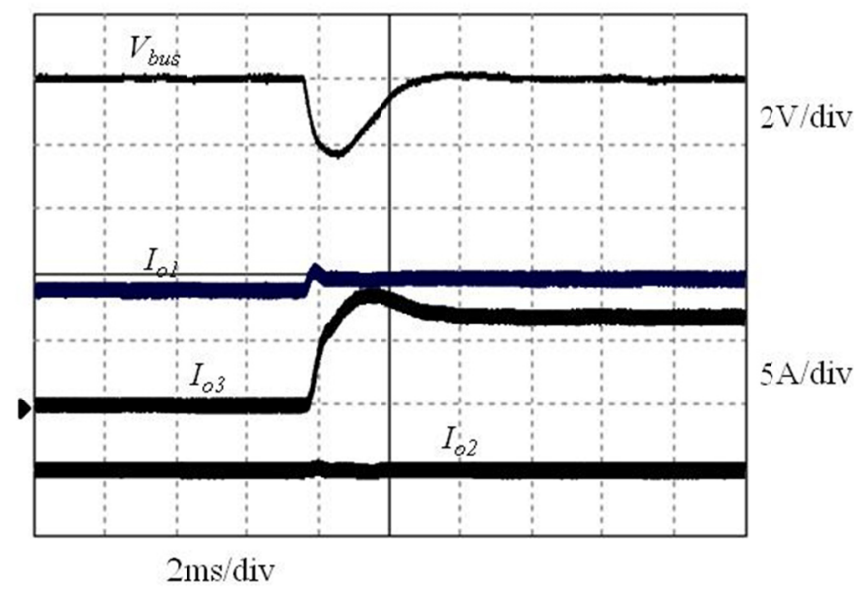

Figure 11. Experimental result of t the capacity limitation control with master-slave and cascaded current command limitation (Converters 1, 3 are in discharge mode and converter 2 is in charge mode,

$$
I_{L} \text { is changed from } 6 \mathrm{~A} \text { to } 13 \mathrm{~A} \text { ) }
$$

\section{Conclusions}

This paper has proposed two methods for parallel control of multiple bi-directional DC-DC converters. They were designed for the charge and discharge control of battery to support the DC bus voltage of the micro-grid system. This paper also provided the implementation and verification with the averaged current control half-bridge converter. The proposed methods can be extended to other converters and other application requiring parallel operation of DC-DC converters.

\section{References}

Augustine, S., Mishra, M. K., \& Lakshminarasamma, N. (2015). Adaptive droop control strategy for load sharing and 
circulating current minimization in low-voltage standalone DC microgrid. IEEE Transactions on Sustainable Energy, 6(1), 1-6. http://dx.doi.org/10.1109/TSTE.2014.2360628

Beshr, E. (2013). Comparative study of adding PV/wind energy systems to autonomous micro grid. 3rd International Conference on Electric Power and Energy Conversion Systems (EPECS).

Dong, D., Cvetkovic, I., Boroyevich, D., Zhang, W., \& Wang, R. (2013). Grid-interface bi-directional converter for residential DC distribution systems - part one: high-density two-stage topology. IEEE Trans. Power Electron., 28(4), 1655-1666. http://dx.doi.org/10.1109/TPEL.2012.2212462

Eid, A. (2013). Control of hybrid energy systems micro-grid. IEEE International Conference on Smart Energy Grid Engineering (SEGE), 1-6. http://dx.doi.org/10.1109/SEGE.2013.6707903

Lasseter, R., Akhil, A., Marnay, C., \& Stevens, J. (2002). The certs microgrid concept - white paper on integration of distributed energy resources. Technical Report, U.S. Department of Energy.

Lu, X., Sun, K., Guerrero, J. M., Vasquez, J. C., \& Huang, L. (2014). State-of-charge balance using adaptive droop control for distributed energy storage systems in DC microgrid applications. IEEE Transactions on Industrial Electronics, 61(6), 2804-2815. http://dx.doi.org/10.1109/TIE.2013.2279374

Lu, X., Sun, K., Huang, L., Guerrero, J. M., Vasquez, J. C., \& Xing, Y. (2014). Virtual Impedance Based Stability Improvement for DC Microgrids with Constant Power Loads. IEEE Energy Conversion Congress and Exposition (ECCE), 2670-2675. http://dx.doi.org/10.1109/ecce.2014.6953759

Luo, S., Ye, Z., Lin, R. L., \& Lee, F. (1999). A classification and evaluation of paralleling methods for power supply modules. IEEE Power Electronics Specialists Conference (PESC), 2, 901-908.

Nasirian, V., Davoudi, A., Lewis, F. L., \& Guerrero, J. M. (2014). Distributed Adaptive Droop Control for DC Distribution Systems. IEEE Transactions on Energy Conversion, 29(4), 944-956. http://dx.doi.org/10.1109/TEC.2014.2350458

Phattanasak, M., Kaewmanee, W., Thounthong, P., Sethakul, P., Martin, J. P., Pierfederici, S., \& Davat, B. (2013). Flatness based control of a dual active bridge converter for DC microgrid. IEEE IECON, 7926-7931. http://dx.doi.org/10.1109/iecon.2013.6700457

Xu, H. G., He, J., Qin, P. Y., \& Li, Y. H. (2012). Energy management and control strategy for DC micro-grid in data center. China International Conference on Electricity Distribution (CICED),1-6. http://dx.doi.org/10.1109/ciced.2012.6508607

Yu, X., Huang, A., Burgos, R., Li, J., \& Du, Y. (2013). A fully autonomous power management strategy for DC microgrid bus voltages. IEEE Applied Power Electronics Conference and Exposition (APEC), 2876-2881. http://dx.doi.org/10.1109/apec.2013.6520706

\section{(cc) BY}

This work is licensed under a Creative Commons Attribution 3.0 License. 